\title{
Antibacterial and antioxidative properties of different parts of garden rhubarb, blackcurrant, chokeberry and blue honeysuckle
}

\section{Raudsepp, Piret}

2019-03-30

Raudsepp , P , Koskar , J , Anton , D , Meremäe , K, Kapp , K, Laurson , P , Bleive , U , Kaldmäe , H , Roasto , M \& Püssa , T 2019 , ' Antibacterial and antioxidative properties of different parts of garden rhubarb, blackcurrant, chokeberry and blue honeysuckle ' , Journal of the Science of Food and Agriculture , vol. 99 , no. 5 , pp. 2311-2320 . https://doi.org/10.1002/jsfa.9429

http://hdl.handle.net/10138/326380

https://doi.org/10.1002/jsfa.9429

unspecified

acceptedVersion

Downloaded from Helda, University of Helsinki institutional repository.

This is an electronic reprint of the original article.

This reprint may differ from the original in pagination and typographic detail.

Please cite the original version. 
1 Antibacterial and antioxidative properties of different parts of garden rhubarb, black currant, chokeberry and blue honeysuckle.

4 Piret Raudsepp ${ }^{\mathrm{a}^{*}}$, Julia Koskar ${ }^{\mathrm{a}, \mathrm{b}}$, Dea Anton ${ }^{\mathrm{a}}$, Kadrin Meremäe ${ }^{\mathrm{a}}$, Karmen Kapp , 5 Peeter Laurson ${ }^{\text {d,e }}$, Uko Bleive $^{\mathrm{e}}$, Hedi Kaldmäe ${ }^{\mathrm{e}}$, Mati Roasto ${ }^{\mathrm{a} \Omega}$, Tõnu Püssa ${ }^{\mathrm{a} \Omega}$

6

7 a Chair of Food Hygiene and Veterinary Public Health, Institute of Veterinary Medicine and Animal Sciences,

8 Estonian University of Life Sciences, Kreutzwaldi 56/3, 51014 Tartu, Estonia

$9 \quad$ beterinary and Food Laboratory, Kreutzwaldi 30, 51006, Tartu, Estonia

*-Corresponding author: Piret Raudsepp; raudsepp.piret@ gmail.com; Kreutzwaldi 56/3, 51014 Tartu, Estonia

$\Omega$-these authors contributed equally to the work 
BACKGROUND: It is important to find plant materials that can inhibit the growth of Listeria monocytogenes and other food spoiling bacteria both in vitro and in situ. The aim of the study was to compare antibacterial and antioxidative activity of selected plant-ethanol infusions: leaves and berries of black currant (Ribes nigrum L.), berries of chokeberry (Aronia melanocarpa (Michx.) Elliott) and blue honeysuckle (Lonicera caerulea L. var. edulis); petioles and dark and light roots of garden rhubarb (Rheum rhaponticum L.), in the perspective to use them further in food matrices as antibacterial and antioxidative additives.

RESULTS: The strongest bacterial growth inhibition was observed in 96\% ethanol infusions of the dark roots of rhubarbs. In $96 \%$ ethanol, nine out of ten studied plant infusions had antibacterial effect against L. monocytogenes, but in $20 \%$ ethanol, only the infusions of dark rhubarb roots had similar effect. Chokeberry and other berries had the highest antioxidative activity, both in $20 \%$ and $96 \%$ ethanol infusions.

CONCLUSION: Combination of dark rhubarb roots and berries of black chokeberry or some other anthocyanin-rich berries would have good perspective as both antibacterial and antioxidative additives in food. 


\section{INTRODUCTION}

Due to the raising customer awareness, there is an increasing trend to seek for new natural food additives that can be used as antibacterial ( $\mathrm{AB}$ ) and/or antioxidative (AO) agents in foods. It is particularly important to find plant materials that can inhibit the growth of Listeria monocytogenes, resistant to many environmental stress factors. In addition, Campylobacter jejuni is highly prevalent bacterium in broiler chicken meat of Baltic origin and the most often reported bacterial cause of human intestinal infections. ${ }^{1}$

Synergistic effect of different polyphenolic compounds is mainly responsible for antimicrobial, ${ }^{2}$ antioxidative,,${ }^{3,4}$ health beneficial ${ }^{5,6,7}$ and plant protective properties ${ }^{8}$ of a plant material. There are studies where polyphenolic composition of rhubarb roots ${ }^{9}$, black currant leaves and berries ${ }^{10,11}$, edible honeysuckle berries ${ }^{12,13}$ and chokeberry berries ${ }^{14,15}$ have been sufficiently described. Kosikowska et al. ${ }^{16}$ and Raudsepp et al. ${ }^{17}$ have shown very strong AB

effect of garden rhubarb roots. Hasper et al. ${ }^{18}$ have established that only minimal toxicity concerns exist regarding the use of garden rhubarb root preparations for human internal consumption.

According to Zheng et al. ${ }^{19}$ and Vagiri et al. ${ }^{11}$, polyphenolic composition of a plant product depends on variety, maturity and part of the plant, weather and processing technology. Raudsepp et al. ${ }^{10}$ and Vagiri et al. ${ }^{20}$ have ascertained that European black currant varieties may have two- to three-fold differences in the anthocyanin content, even if grown at the same conditions. Differences in total polyphenolic and total anthocyanin content may result in significantly different $\mathrm{AB}, \mathrm{AO}$ and other properties of the plant products. Therefore, it is important to conduct the selection among the cultivars and plant parts to choose the ones with the highest beneficial properties ${ }^{21}$.

61 The aim of this study was to gain comparable information about in vitro $\mathrm{AB}$ and radical scavenging activities of different plant species and their different parts. The more successive 
aim was to select plant materials for further use as antimicrobials or AO compounds in foods. Results of the preceding studies were reviewed, the plant species and their varieties with multiple beneficial capacities and high horticultural relevance in the Northern Europe were selected. In particular, the highest anthocyanin content of the cultivated berries and high $\mathrm{AB}$ or AO activity of other plant parts were taken into account. The $20 \%$ and $96 \%$ ethanol concentrations in the infusions were chosen to compare the summary effects of hydrophilic and more hydrophobic polyphenol complexes.

According to our knowledge, this is the first study, where ethanol infusions of abovementioned plants and their different parts were comparatively analysed for $\mathrm{AB}$ and $\mathrm{AO}$ activities.

\section{EXPERIMENTAL}

\section{The plant material}

The planting material of rhubarb varieties was obtained from the collection of Pūre Horticultural Research Centre, Latvia. All studied plants were grown in the plantation of Polli Horticultural Research Centre, Estonia $\left(58^{\circ} 06^{\prime} \mathrm{N}^{\circ} 25^{\circ} 32^{\prime} \mathrm{E}\right)$. Two dark-rooted rhubarbs ('Victoria' and seedling 303) and one light-rooted ('Ogres') rhubarb were selected among 16 different cultivars or seedlings, according to the content of hydroxyanthraquinones. Berries of chokeberry (selected among three seedlings), blue honeysuckle (haskap berry) 'Tomitška' (selected among five cultivars) and black currant 'Ben Alder' (selected among 37 cultivars); leaves of black currant 'Pamyati Vavilova' and petioles of abovementioned garden rhubarbs were freeze-dried with VirTis AdVantage 2.0 EL freeze-dryer (SP Industries, Warminster, USA) and kept at the temperature $-40^{\circ} \mathrm{C}$ until powdering. The roots of garden rhubarb cultivars and seedling were washed, diced and dried at $50^{\circ} \mathrm{C}$ in a drying oven (Binder FED101, Binder $\mathrm{GmbH}$, Tuttlingen, Germany) and kept at room temperature. 
All dried plant materials were powdered with a blender (Stollar/Kinetix ${ }^{\circledR}$ Control) to the particle size diameter $\leq 3 \mathrm{~mm}$, the necessary fraction was obtained with the analytical sieve shaker AS300 control (Retsch GmbH, Germany). For the infusions, $1 \mathrm{~g}$ of each powder in duplicate were mixed with $20 \mathrm{~mL}$ of $20 \%$ and $96 \%$ of aqueous ethanol. The mixtures were rotated on Multi RS-60 Multirotator (Biosan, Riga, Latvia) at $40 \mathrm{rpm}$ for $24 \mathrm{~h}$ at the room temperature, followed by centrifugation at $2594 \mathrm{~g}$ for $10 \mathrm{~min}$ on Sigma 4-16KS (Sigma Laborzentrifugen $\mathrm{GmbH}$, Germany) centrifuge. The supernatants were collected and further diluted by two, four and eight times for the estimation of $\mathrm{AB}$ and $\mathrm{AO}$ properties, and for quantitation of total polyphenols content (TPC) and total anthocyanins. In addition, transrhapontin (Merck), rutin (Sigma), trans-resveratrol (Sigma) and emodin (Sigma) as single phenolic compounds were included into the $\mathrm{AB}$ and $\mathrm{AO}$ studies at four concentrations: 0.125; 0.25; 0.5 and $1 \mathrm{~g} \cdot \mathrm{L}^{-1}$. TPC and anthocyanin content of plant infusions were estimated by areas under HPLC-UV chromatographic curves at 280 and $520 \mathrm{~nm}$, respectively ${ }^{22}$, using UHPLCMS Shimadzu Nexera X2 system (Shimadzu Scientific Instruments, Kyoto, Japan). For the estimation of TPC and anthocyanin content, chlorogenic acid (Aldrich) and cyanidin 3-Oglucoside chloride (kuromanin chloride, Sigma) calibration curves were used, respectively. The qualitative analyse of plant extracts and the content of ascorbic acid (AA) and citric acid (CA) were analysed with 1100 Series LC/MSD Trap-XCT (Agilent Technologies, Santa Cruz, CA, USA) using AA (Sigma) and CA (Sigma) as calibration standards ${ }^{17}$. Total acidity and total sugar content were estimated with the FTIR spectrometer Bruker ALPHA ATR Platinum system (Bruker Optics GmbH, Germany). The AO of the infusions were measured using DPPH radical scavenging method ${ }^{23}$, AO activities were expressed in rutin equivalents $\left(\mathrm{g} \cdot \mathrm{L}^{-1}\right)$. Additionally, $\mathrm{pH}$ values of the $20 \%$ ethanol infusions were measured. 


\section{The bacterial strains}

$114 \mathrm{AB}$ effect of plant infusions was determined against Gram-negative Campylobacter jejuni ATCC 33291, Salmonella Enteritidis ATCC 13076, Escherichia coli NCCB 100282, Yersinia ruckeri NCIM 13282 and Gram-positive Listeria monocytogenes ATCC 13929, Bacillus cereus ATCC 11778, Kocuria rhizophila ATCC 9341, Bacillus subtilis BGA and Bacillus pumilus CV 607 bacteria, obtained from the collections of the Estonian Veterinary and Food Laboratory and the Chair of Food Hygiene and Veterinary Public Health of Estonian University of Life Sciences.

\section{The antibacterial activity $(\mathrm{AB})$ test}

$\mathrm{AB}$ activity testing was performed by modified agar well-diffusion method as previously described by Raudsepp et al. ${ }^{17}$. In case of $C$. jejuni, L. monocytogenes, S. Enteritidis and E. coli, the suspensions with final density of $10^{5}-10^{6}$ per $\mathrm{mL}$ were prepared and, using sterile swabs, transferred uniformly onto the agar surface, for $C$. jejuni a sterile spatula was used. In case of B. cereus, Y. ruckeri, K. rhizophila, B. subtilis and B. pumilus, definite amount of incubated bacterial suspension was mixed with $400 \mathrm{~mL}$ of sterilized and thereafter cooled down to $45^{\circ} \mathrm{C}$ Mueller-Hinton agar (Oxoid), to obtain final density of $10^{5}-10^{6} \mathrm{cfu} \cdot \mathrm{mL}^{-1}$ and then poured onto Petri dishes for the solidification at the room temperature. Thereafter, the wells $(5 \mathrm{~mm}$ in

131 diameter) were made into agar gel using sterile tools. Subsequently, the wells were filled with $13230 \mu \mathrm{L}$ of plant ethanol infusion in four different dilutions: 1:20 (w/v), 1:40, 1:80 and 1:160. Plates were incubated under conditions described in Table 1, the diameter of inhibition zone in millimetres was measured and the $\mathrm{AB}$ effect of a plant ethanol infusion was calculated as a mean of duplicate tests. As negative controls, $20 \%$ and $96 \%$ ethanol were used, and as a positive control, chloramphenicol (LAB M; $1000 \mathrm{mg} \cdot \mathrm{L}^{-1}$ ) was used. 
138 [Insert table 1 here]

\section{Statistical analysis}

141 MS Excel 2013 software was used to evaluate the correlations between different chemical

142 properties and $\mathrm{AB}$ activities of the infusions. Correlation was considered strong, if $\mathrm{r}$ was equal 143 or higher than \pm 0.65 , moderate if $r \geq \pm 0.41$ to \pm 0.64 or weak if the $r$ value was in the interval 0 144 to \pm 0.4 .

\section{RESULTS AND DISCUSSION}

\section{Chemical composition of plant infusions}

148 The total polyphenol content (TPC) of the plant infusions (1:20, w/v) varied from 0.18 to 5.21

$149 \mathrm{~g} \cdot \mathrm{L}^{-1}$ in $20 \%$ ethanol infusions and from 0.06 to $7.03 \mathrm{~g} \cdot \mathrm{L}^{-1}$ in $96 \%$ ethanol infusions, rhubarb

150 petioles being the lowest and rhubarb 'Victoria' roots the highest in TPC (Fig. 1). The

151 anthocyanin content varied from 0 to $0.83 \mathrm{~g} \cdot \mathrm{L}^{-1}$ and from 0 to $1.87 \mathrm{~g} \cdot \mathrm{L}^{-1}$ in $20 \%$ and $96 \%$ ethanol

152 infusions respectively, chokeberry having the highest anthocyanin content in $20 \%$ ethanol and

153 blue honeysuckle in $96 \%$ ethanol. The ascorbic acid content varied from 0.31 to $2.14 \mathrm{~g} \cdot \mathrm{L}^{-1}$ in

$15420 \%$ ethanol and from 0.16 to $2.4 \mathrm{~g} \cdot \mathrm{L}^{-1}$ in $96 \%$ ethanol, chokeberry having the lowest and blue

155 honeysuckle the highest in $20 \%$ ethanol and black currant berries the highest AA content in

$15696 \%$ ethanol. The $\mathrm{pH}$ of studied infusions varied from 3.15 (black currant berries) to 3.8

157 (petioles of rhubarb 'Victoria'). The infusions of the berries and the rhubarb petioles contained

158 anthocyanins, rhubarb roots and black currant leaves did not (Fig. 1). It was noted that the dark-

159 rooted rhubarb cultivars had more anthocyanins in their petioles than the light-rooted cultivars 
160

161

162

163

164

165

166

167

168

169

170

171

172

173

174

175

176

177

178

179

180

181

182

183

(Fig. 1). The total acidity was highest in the petioles of rhubarb 'Ogres' $\left(8.7 \mathrm{~g} \cdot \mathrm{L}^{-1}\right)$ and the sugar acid ratio was the highest in chokeberry berries (6.3), followed by blue honeysuckle berries (4.4). Blue honeysuckle had the highest content of total sugars $\left(24.3 \mathrm{~g} \cdot \mathrm{L}^{-1}\right)$, which exceeded black currant and chokeberry berries approximately by $6 \mathrm{~g} \cdot \mathrm{L}^{-1}$. The qualitative analyse of the plant extracts revealed that the polyphenolic composition of the plants differed notably, containing polyphenols with different properties (Table 2, Fig. 2), hence some differences in the $\mathrm{AO}$ and $\mathrm{AB}$ properties.

[Insert Figure 1 and 2 and table 2. here]

\section{Antibacterial (AB) effect}

The in vitro $\mathrm{AB}$ activities, in the form of the diameters of growth inhibition zones of selected plant infusions were determined against both Gram-positive (Table 3) and Gram-negative (Table 4) bacteria. The results indicated remarkable in vitro $\mathrm{AB}$ effect of several plant infusions (Fig. 3). In case of $20 \%$ ethanol-plant infusions, the Gram-negative bacteria were less susceptible than Gram-positive bacteria. This is in agreement with Goňi et al. ${ }^{24}$, who reported Gram-negative bacteria being generally less susceptible to different antibacterial agents due to the outer lipopolysaccharide membrane, which restricts the diffusion of hydrophilic compounds into the bacterial cell. However, Taguri et al. ${ }^{25}$ have concluded that the result of Gram-staining does not correlate with $\mathrm{AB}$ effect, and susceptibility of bacteria, growing in Mueller-Hinton medium depends mostly on the particular bacterial species. In the present study it was found that the strongest $\mathrm{AB}$ activity of tested plant $96 \%$ ethanol infusions were against C. jejuni, which is a Gram-negative micro-aerobic bacterium, also against B. cereus, which is a Grampositive aerobic bacterium, with inhibition zones $18 \mathrm{~mm}$ and $15.5 \mathrm{~mm}$, respectively. 
185 [Insert Figure 3 here]

Against Gram-negative bacteria C. jejuni, S. Enteritidis and E. coli, the most effective at all tested dilutions were $96 \%$ ethanol infusions of the roots and petioles of the dark-rooted rhubarb 303 and the roots of 'Victoria' with inhibition zone diameters 7-18 mm (Fig. 3). Weaker AB effects of the same plant infusions against the abovementioned bacteria were established in $20 \%$ ethanol (Fig. 3). Regarding Y. ruckeri, the infusions of the petioles of dark rhubarb no 303 in $96 \%$ and $20 \%$ ethanol were equally effective (Table 4).

The most effective against all studied Gram-positive bacteria was $96 \%$ ethanol infusion of the roots of dark rhubarb seedling 303, inhibition zone diameters were in the range of $8-15.5 \mathrm{~mm}$ at all dilutions. Among Gram-positive bacteria, B. cereus was the most susceptible to all ten tested plant infusions in $20 \%$ as well as in $96 \%$ ethanol (Fig. 2, Table 3). It is notable that factors, was susceptible to nine out of ten tested $96 \%$ ethanol infusions. Generally, more concentrated infusions (w/v) 1:20 or 1:40 had stronger $\mathrm{AB}$ or bacteriostatic effects against tested bacteria (Table 3).

It has been shown that solubility in water is a significant factor determining the extent to which hydrophobic compounds can be accumulated up to damaging lethal levels in bacterial cell phospholipid membranes ${ }^{24,26}$. In the current study, plant ethanol infusions were used, therefore, the mode of action of antibacterial agents cannot be explained only by cell membrane damage. Trans-resveratrol and emodin, both constituents of rhubarb roots, showed AB activity against gram-negative $C$. jejuni, S. Enteritidis, and E. coli, and against gram-positive L. monocytogenes at their highest used concentration $\left(1 \mathrm{~g} \cdot \mathrm{L}^{-1}\right)$. Li et al. ${ }^{27}$ have estimated by cell membrane permeability and flow cytometry assays ability of hydrophobic emodin (the octanol-water 
partition coefficient $\log \mathrm{K}_{\mathrm{ow}}+4.01$ ECHA $^{28}$ ) to destroy cell membrane integrity and increase

210 membrane permeability; fluorescence spectroscopy assay had indicated ability of emodin to

211 influence conformation of membrane proteins in case of Gram-positive Haemophilus parasuis.

212 These mechanisms can possibly be used also for explanation of $\mathrm{AB}$ effect against Gram-

213 negative bacteria of rhubarb root $96 \%$ ethanol infusion that, in addition to emodin, contains

214 several other relatively hydrophobic hydroxyanthraquinones ${ }^{9}$.

215 Important finding of the present study was that Gram-positive foodborne pathogenic bacteria

L. monocytogenes and B. cereus as well as Gram-negative pathogens C. jejuni, S. Enteritidis

217 and E. coli were inhibited by the ethanol infusions of the roots and petioles of rhubarb (both

218 seedling 303 and 'Victoria'), which makes rhubarb a promising candidate for the use as the

219 source of natural antibacterials in food. In rhubarb, presumably hydroxyanthraquinones are the

220 major active components having many biological and pharmacological properties including $\mathrm{AB}$

221 activity ${ }^{29,30}$. In the study of Lu et al. ${ }^{2}$, the minimum inhibitory concentration (MIC) of crude

222 extracts of rhubarb was positively related to the hydroxyanthraquinones' content, and similarly

223 to the results of the current study it was found that rhubarb may have the potential use as an

224 antibacterial agent for control of some pathogenic bacteria.

226 [Insert Table 3 and Table 4 here]

\section{The free radical scavenging ability}

229 The highest antioxidativity (AO), expressed by the DPPH free radical scavenging activity, had 230 chokeberry berries with the highest content and variability of anthocyanins, both in $20 \%$ and

$23196 \%$ aqueous ethanol infusions, that is in correspondence with the results of Tian et al. ${ }^{21}$

232 Chokeberry was followed by $20 \%$ aqueous ethanol infusion of black currant berries with the 
lowest total polyphenols and total anthocyanins among the berries. Obviously, AO properties

234 of black currant berries are primarily dependent on the hydrophilic compounds such as ascorbic 235 acid $^{20}$, and subsequently on semi-polar anthocyanins ${ }^{3,13}$ and flavon-3-ols, particularly rutin ${ }^{31}$, 236 all of which are good antioxidants and better extractable with a more hydrophilic solvent (20\% 237 ethanol). Honeysuckle with the highest total polyphenol content among berries and dark 238 rhubarb roots (Fig. 1, b) with the absolutely highest TPC, were also efficient. The AO properties 239 of chokeberry, black currant berries and blue honeysuckle berries were however very similar 240 (Fig 1). In the case of rhubarb roots, AO is obviously more dependent on relatively hydrophobic 241 constituents like hydroxyanthraquinones emodin, aloe emodin, and chrysophanol as well as 242 resveratrol di- and trimers ${ }^{9,32}$, which are extractable from the plant matrix with a more nonpolar 243 solvent such as $96 \%$ ethanol. The content of anthocyanins was positively correlated with the 244 AO of both $20 \%(\mathrm{r}=0.65)$ and $96 \%(\mathrm{r}=0.47)$ ethanol infusions of the plants (Fig. 4), that is in 245 the correspondence with the results of Heinonen et al. ${ }^{3}$ and Shih et al. ${ }^{33}$ Also, content of citric 246 and ascorbic acids, both outstanding transition metal chelators, had moderate positive 247 correlation with free radical scavenging activities of the plant infusions (Fig. 4). It has been 248 stated that organic acids, including citric acid, generally enhance the DPPH radical scavenging 249 activity of ascorbic acid at the steady rate, whereas citric acid slows it down during the first 250 minute of the reaction ${ }^{34}$. In the current study, the TPC in the plant infusions was weakly 251 positively correlated with AO properties (Fig. 4) that may be caused by the high content of 252 hydroxyanthraquinones and stilbenes in rhubarb root that have very strong $\mathrm{AB}^{2,16}$, but weaker 253 radical scavenging capacity ${ }^{32}$. In berries the bulk of the TPC were anthocyanins - strongly 254 antioxidative molecules ${ }^{3,33}$, but not equally good antibacterial compounds.

255 The AO properties of the studied polyphenol standard compounds were in the descending order 256 rutin > trans-resveratrol > trans-rhapontin > emodin, which is in agreement with Villaño et 257 al. ${ }^{35}$. 
[Insert Figure 4 here]

\section{CONCLUSIONS}

262 The roots and petioles of rhubarb showed the highest $A B$ activity against studied bacteria that

263 highlights rhubarb as a promising candidate for the use as a source of natural antibacterials in

264 food, if possible contamination by the soil microflora has been reduced to minimum. The

265 highest in vitro $\mathrm{AB}$ activities were measured for dark roots of rhubarb infusions in $96 \%$ ethanol.

266 Also, trans-resveratrol and emodin, as single compounds, both present in rhubarb roots,

267 revealed remarkable $\mathrm{AB}$ activity against studied bacteria.

268 AB activity was more strongly correlated with total polyphenolic content of the plant infusions

269 than with the total content of anthocyanins On the other hand, the highest AO activity was

270 determined for plant materials containing anthocyanins The $\mathrm{AB}$ and $\mathrm{AO}$ of the studied plant

271 infusions were not unambiguously correlated indicating that different compounds may be

272 involved in antioxidative properties compared to antibacterial properties.

273 Combination of powders of dark rhubarb roots and petioles with berries of black chokeberry,

274 black currant or some other anthocyanin-rich berries would have outstanding perspective to use

275 as functional ingredients in food matrices.

\section{ACKNOWLEDGEMENTS}

277 The research was financially supported by EU ERA-NET SUSFOOD project "Sustainable plant

278 ingredients for healthier meat products -proof of concepts" (SUSMEATPRO), and basic

279 financing project "Metabolomics, antioxidative and antibacterial activity, and related

280 mechanisms of food plants "of Estonian University of Life Sciences P170054VLTH. 
281

The authors thank Liga Lepse from Latvian University of Agriculture; Hans Neppo, Liina Arus and Kersti Kahu from Polli Horticultural Research Centre, Estonian University of Life Sciences, for technical help with plant material.

\section{REFERENCES}

1. Kovalenko K, Roasto M, Liepinš E, Mäesaar M and Hörman A, High occurrence of Campylobacter spp. in Latvian broiler chicken production. Food Control 29: 188-191 (2013).

2. Lu C, Wang H, Lv W, Xu P, Zhu J, Xie J, Liu B and Lou Z, Antibacterial properties of anthraquinones extracted from rhubarb against Aeromonas hydrophila. Fish Sci 77: 375-384 (2011).

3. Heinonen M, Antioxidant activity and antimicrobial effect of berry phenolics - a Finnish perspective. Mol Nutr Food Res 51: 684-691 (2007).

4. Skrovankova S, Sumczynski D, Mlcek J, Jurikova T and Sochor J, Bioactive compounds and antioxidant activity in different types of berries. Int J Mol Sci 16: 24673-24706 (2015).

5. He Z-H, He M-F, Ma S-C and But PP-H, Anti-angiogenic effects of rhubarb and its anthraquinone derivatives. J Ethnopharmacol 121: 313-317 (2009).

6. Neyrinck AM, Etxeberria U, Taminiau B, Daube G, Van Hul M, Everard A, Cani PD, Bindels LB and Delzenne NM, Rhubarb extract prevents hepatic inflammation induced by acute alcohol intake, an effect related to the modulation of the gut microbiota. Mol Nutr Food Res 61: 1-12 (2016).

7. Celli GB, Ghanem A and Brooks MS-L, A theoretical physiologically based pharmacokinetic approach for modeling the fate of anthocyanins in vivo. Crit Rev Food Sci Nutr 57: 3197-3207 (2017). 
8. Stephan D, Schmitt A, Martins Carvalho S, Seddon B and Koch E, Evaluation of biocontrol preparations and plant extracts for the control of Phytophthora infestans on potato leaves. Eur J Plant Pathol 112: 235-246 (2005).

9. Püssa T, Raudsepp P, Kuzina K and Raal A, Polyphenolic composition of roots and petioles of Rheum rhaponticum L. Phytochem Anal 20: 98-103 (2009).

10. Raudsepp P, Kaldmäe H, Kikas A, Libek A-V and Püssa T, Nutritional quality of berries and bioactive compounds in the leaves of black currant (Ribes nigrum L.) cultivars evaluated in Estonia. J Berry Res 1: 53-59 (2010).

11. Vagiri M, Conner S, Stewart D, Andersson SC, Verrall S, Johansson E and Rumpunen K, Phenolic compounds in blackcurrant (Ribes nigrum L.) leaves relative to leaf position and harvest date. Food Chem 172: 135-142 (2015).

12. Chaovanalikit A, Thompson MM and Wrolstad RE, Characterization and quantification of anthocyanins and polyphenolics in blue honeysuckle (Lonicera caerulea L.). J Agric Food Chem 52: 848-852 (2004).

13. Caprioli G, Iannarelli R, Innocenti M, Bellumori M, Fiorini D, Sagratini G, Vittori S,

D, Cavallucci C, Bistoni O, Trivisonno A and Maggi F, Blue honeysuckle fruit (Lonicera caerulea L.) from eastern Russia: phenolic composition, nutritional value and biological activities of its polar extracts. Food Funct 7: 1892-1903 (2016).

324 Phenolic content, antioxidant capacity, radical oxygen species scavenging and lipid peroxidation inhibiting activities of extracts of five black chokeberry (Aronia melanocarpa (Michx.) Elliot) cultivars. J Med Plants Res 4: 2431-2437 (2010). 
15. Tian Y, Liimatainen J, Alanne A-L, Lindstedt A, Liu P, Sinkkonen J, Kallio H and Yang B,

328 Phenolic compounds extracted by acidic aqueous ethanol from berries and leaves of different berry plants. Food Chem 220: 266-281 (2017).

16. Kosikowska U, Smolarz HD and Malm A, Antimicrobial activity and total content of polyphenols of Rheum L. species growing in Poland. Cent Eur J Biol 5: 814-820 (2010). (Lonicera caerulea L.), Siberian rhubarb (Rheum rhaponticum L.) and some other plants, compared to ascorbic acid and sodium nitrite. Food Control 31: 129-135 (2013). Long-term efficacy and safety of the special extract ERr 731 of Rheum rhaponticum in perimenopausal women with menopausal symptoms. Menopause 16: 117-31 (2009).

19. Zheng J, Yang B, Ruusunen V, Laaksonen O, Tahvonen R, Hellsten J and Kallio H, Compositional Differences of Phenolic Compounds between Black Currant (Ribes nigrum L.)

Cultivars and Their Response to Latitude and Weather Conditions. J Agric Food Chem 60: $6581-6593(2012)$

20. Vagiri M, Ekholm A, Öberg E, Johansson E, Andersson SC and Rumpunen K, Phenols and ascorbic acid in black currant (Ribes nigrum L.): variation due to genotype, location and year. J Agric Food Chem 61: 9298-9306 (2013). antibacterial activities of aqueous ethanol extracts of berries, leaves, and branches of berry plants. Food Res Int 106: 291-303 (2018) 
350 Commercial peppermint (Mentha $\times$ piperita L.) teas: Antichlamydial effect and polyphenolic composition. Food Res Int 53: 758-766 (2013).

23. Helmja K, Vaher M, Püssa T, Raudsepp P and Kaljurand M, Evaluation of antioxidative capability of the tomato (Solanum lycopersicum) skin constituents by capillary electrophoresis and high-performance liquid chromatography. Electrophoresis 29: 3980-3988 (2008).

24. Goňi P, Lopez P, Sanchez C, Gomez-Lus R, Becerril R and Nerin C, Antimicrobial activity in the vapour phase of a combination of cinnamon and clove essential oils. Food Chem 116: 982-989 (2009).

25. Taguri T, Tanaka T and Kouno I, Antibacterial spectrum of plant polyphenols and extracts depending upon hydroxyphenyl structure. Biol Pharm Bull 29: 2226-2235 (2006).

26. Cox SD, Mann CM and Markham JL, Interactions between components of the essential oil of Melaleuca alternifolia. J Appl Microbiol 91: 492-497 (2001).

27. Li L, Song X, Yin Z, Jia R, Li Z, Zhou X, Zou Y, Li L, Yin L, Yue G, Ye G, Lv C, Shi W and $\mathrm{Fu} \mathrm{Y}$, The antibacterial activity and action mechanism of emodin from Polygonum cuspidatum against Haemophilus parasuis in vitro, Microbiol Res 186-187: 139-145 (2016).

28. ECHA, European Chemicals Agency, Registration dossier. Anthraquinone. Toxicity to soil macroorganisms except arthropods. (2011) https://echa.europa.eu/registration-dossier//registered-dossier/5769/6/4/2/ [24 October 2017].

29. Iizuka A, Iijima OT, Kondo K, Itakura H, Yoshie F, Miyamoto H, Kubo M, Higuchi M, Takeda $\mathrm{H}$ and Matsumiya T, Evaluation of rhubarb using antioxidative activity as an index of pharmacological usefulness. J Ethnopharmacol 91: 89-94 (2004). 
371 30. Wang J, Zhao H, Kong W, Jin C, Zhao Y, Qu Y and Xiao X, Micro calorimetric assay on

372 the antimicrobial property of five hydroxyanthraquinone derivatives in rhubarb (Rheum 373 palmatum L.) to Bifidobacterium adolescentis. Phytomedicine 17: 684-689 (2010).

374 31. Afanas'ev IB, Dcrozhko AI, Brodskii AV, Kostyuk VA, and Potapovitch AI, Chelating and 375 free radical scavenging mechanisms of inhibitory action of rutin and quercetin in lipid 376 peroxidation. Biochem Pharmacol 38: 1763-1769 (1989).

377 32. Yen G-C, Duh P-D and Chuang D-Y, Antioxidant activity of anthraquinones and anthrone. 378 Food Chem 70: 437-441 (2000).

379 33. Shih P-H, Yeh C-T and Yen GC, Anthocyanins induce the activation of phase II enzymes 380 through the antioxidant response element pathway against oxidative stress-induced apoptosis. 381 J Agric Food Chem 55: 9427-9435 (2007).

382 34. Lo Scalzo R, Organic acids influence on DPPH, scavenging by ascorbic acid. Food Chem 383 107: 40-43. (2008).

384 35. Villaño D, Fernández-Pachón MS, Moyá ML, Troncoso AM and García-Parrilla MC, 385 Radical scavenging ability of polyphenolic compounds towards DPPH free radical. Talanta 71: $386 \quad 230-235(2007)$. 
Figure 1. Chemical content and properties $\left(g \cdot \mathrm{L}^{-1}\right)$ of the plant infusions $(1: 20, \mathrm{w} / \mathrm{v})$ : total 389 polyphenols (TPC), total anthocyanins (Anth.), ascorbic acid (AA), and antioxidativity (AO) in 390 rutin equivalents $\left(\mathrm{g} \cdot \mathrm{L}^{-1}\right)$ of $20 \%$ ethanol infusions (a) and of $96 \%$ ethanol infusions (b). Bars are listed in the descending order of AO.

Figure 2. The base peak chromatograms of the studied plant extracts in $20 \%$ ethanol. The peak numbers are described in the table 2 .

Figure 3. The bacterial growth inhibition zone diameters $(\mathrm{mm})$ of the plant infusions $(1: 20$, $\mathrm{w} / \mathrm{v}$ ) in $20 \%$ and $96 \%$ ethanol, against each bacteria, listed in the descending order of summarized $\mathrm{AB}$ activities.

Figure 4. Correlations between characteristics of plant infusions in $20 \%$ and $96 \%$ ethanol solutions. TPC-Anth.-Total polyphenol content minus anthocyanins' content, AB-antibacterial

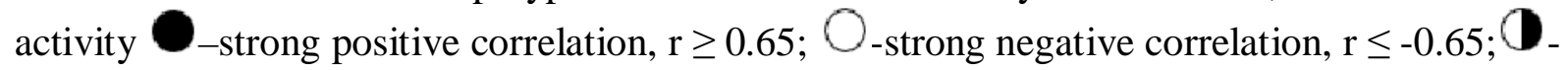

403 weak correlation, $\mathrm{r} \sim 0$ to $\pm 0.4 ; \boldsymbol{Q}$ - moderate positive correlation, $\mathrm{r}=0.41$ to $0.64 ; \boldsymbol{\Theta}$-moderate 404 negative correlation, $\mathrm{r}=-0.64$ to -0.41 
407 Table 1. Used media and incubation conditions for different bacteria

\begin{tabular}{|c|c|c|}
\hline Bacterial culture & Agar-media & Incubation conditions \\
\hline \multicolumn{3}{|l|}{ Gram negative } \\
\hline $\begin{array}{l}\text { Campylobacter jejuni } \\
\text { ATCC } 33291\end{array}$ & $\begin{array}{l}\text { Columbia blood agar (Oxoid) }+ \\
5 \% \text { lysed horse blood (Oxoid) }\end{array}$ & $42{ }^{\circ} \mathrm{C}, 48 \mathrm{~h}$, micro aerobic \\
\hline $\begin{array}{l}\text { Salmonella Enteritidis } \\
\text { ATCC } 13076\end{array}$ & Mueller Hinton agar (Oxoid) & $37^{\circ} \mathrm{C}, 48 \mathrm{~h}$, aerobic \\
\hline $\begin{array}{l}\text { Escherichia coli NCCB } \\
100282\end{array}$ & Mueller Hinton agar (Oxoid) & $37^{\circ} \mathrm{C}, 48 \mathrm{~h}$, aerobic \\
\hline $\begin{array}{l}\text { Yersinia ruckeri NCIM } \\
13282\end{array}$ & Plate-count agar (Difco), pH 6.5 & $30^{\circ} \mathrm{C}, 24-26 \mathrm{~h}$, aerobic \\
\hline \multicolumn{3}{|l|}{ Gram positive } \\
\hline $\begin{array}{l}\text { Listeria monocytogenes } \\
\text { ATCC } 13929\end{array}$ & Mueller Hinton agar (Oxoid) & $37^{\circ} \mathrm{C}, 48 \mathrm{~h}$, aerobic \\
\hline $\begin{array}{l}\text { Bacillus cereus ATCC } \\
11778\end{array}$ & $\begin{array}{l}\text { Iso-Sensitest Agar (Oxoid), pH } 6 \\
+625 \mu \mathrm{g} / \mathrm{l} \mathrm{CAP}\end{array}$ & $30^{\circ} \mathrm{C}, 24-26 \mathrm{~h}$, aerobic \\
\hline Kocuria rhizophila & Iso-Sensitest Agar (Oxoid), $\mathrm{pH} 8$ & $37^{\circ} \mathrm{C}, 24-26 \mathrm{~h}$, aerobic \\
\hline Bacillus subtilis BGA & Plate-count agar (Difco), pH 8 & $37^{\circ} \mathrm{C}, 24-26 \mathrm{~h}$, aerobic \\
\hline Bacillus pumilus CV 607 & DST-agar (Oxoid), pH 7 & $37^{\circ} \mathrm{C}, 24-26 \mathrm{~h}$, aerobic \\
\hline
\end{tabular}


409 Table 2. The qualitative composition of the studied plants' $20 \%$ ethanol extracts, analysed 410 with negative and/or positive ion mode. The most potent antioxidative compounds

411 (unpublished data) are marked in bold. The peak numbers are referring to the Fig. 2. *-the 412 compound is better extractable with $96 \%$ ethanol compared to $20 \%$ ethanol.

\begin{tabular}{|c|c|c|}
\hline Peak no. & The most abundant compounds in Ribes nigrum leaves & {$[\mathrm{M}-\mathrm{H}]-/$ fragments } \\
\hline 1 & Catechin gallate & $305 / 179 ; 219 ; 261 ; 137$ \\
\hline 2 & Chlorogenic acid I & $353 / 191 ; 179$ \\
\hline 3 & Dihydro ferulic acid rhamnoside & $341 / 195 ; 163 ; 129$ \\
\hline 4 & Chlorogenic acid II & $353 / 191$ \\
\hline 5 & Ferulic acid derivative & 399/193;301 \\
\hline 6 & Coumaryl quinic acid & $337 / 191$ \\
\hline 7 & Coumaroylquinic acid pentoside & $675 / 337 ; 191$ \\
\hline 8 & Myricetin-glucoside & $479 / 317 ; 179 ; 151$ \\
\hline 9 & Quercetin-3-rutinoside syn. Rutin & $609 / 301$ \\
\hline 10 & Quercetin glucoside & $463 / 301$ \\
\hline 11 & Quercetin acetylglucoside & $505 / 301$ \\
\hline 12 & Kaempferol rutinoside & $593 / 285$ \\
\hline 13 & Kaempferol-3-0-glucoside & $447 / 285$ \\
\hline 14 & Kaempferol acetylglucoside & $489 / 285$ \\
\hline 15 & Isorhamnetin acetylglucoside & $519 / 315$ \\
\hline 16 & Chrysophanol glucoside & $415 / 373 ; 355$ \\
\hline 17 & Oxylipin & $327 / 311 ; 211 ; 171$ \\
\hline 18 & Oxylipin 9S,12S,13S-trihydroxy-10E-octadecenoic acid (9,12,13-TriHOME) & $329 / 311 ; 211 ; 171$ \\
\hline Peak no. & The most abundant compounds in Rheum rhaponticum roots & {$[\mathrm{M}-\mathrm{H}]$-/fragments } \\
\hline 1 & Procyanidin B1 & $577 / 407 ; 289$ \\
\hline 2 & Catechin & $289 / 245$ \\
\hline 3 & Epicatechin & $289 / 245$ \\
\hline 4 & Piceatannol-0-glucoside 1 & $405 / 243$ \\
\hline 5 & Resveratrol-0-glucoside & $389 / 227$ \\
\hline 6 & Piceatannol-0-glucoside 2 & $405 / 243$ \\
\hline 7 & Piceid & $389 / 227$ \\
\hline 8 & Piceatannol & $243 / 225$ \\
\hline 9 & Rhapontigenin-0-glucoside 1 & $419 / 257$ \\
\hline 10 & Rhapontigenin-0-glucoside 2 & $419 / 257$ \\
\hline 11 & Rhapontigenin-0-glucoside 3 & $419 / 257$ \\
\hline $12 *$ & Aloe-emodin-O-glucoside & $431 / 269$ \\
\hline 13 & Rhapontigenin & $257 / 241$ \\
\hline $14 *$ & Torachryson-0-glucoside & $407 / 245$ \\
\hline $15^{*}$ & Emodin-O-glucoside & $431 / 269$ \\
\hline 16 & Deoxyrhapontigenin-0-galloylglucosde & $555 / 313 ; 169$ \\
\hline $17 *$ & Torachrysone-0-acetylglucoside & $449 / 245$ \\
\hline $18 *$ & Chrysophanol-O-glucoside & $415 / 253$ \\
\hline 19* & Rhein-0-glucoside & $445 / 283$ \\
\hline $20 *$ & Chrysophanol-0-acetylglucoside & $457 / 253$ \\
\hline 21 & Deoxyrhapontigenin & $241 / 226$ \\
\hline 22 & Resveratrol dimer & $453 / 453$ \\
\hline
\end{tabular}


Table 2. continued.

\begin{tabular}{|c|c|c|c|}
\hline Peak no. & The most abundant compounds in Rheum rhaponticum petioles & {$[\mathrm{M}-\mathrm{H}]$-/fragments } & {$[\mathrm{M}+\mathrm{H}] \mathrm{H} /$ fragments } \\
\hline 1 & Citric acid & 191/111;173 & \\
\hline 2 & Gallic acid & $331 / 169$ & \\
\hline 3 & Catechin & $289 / 245$ & \\
\hline 4 & Paracoumaric acid-glucoside & $325 / 145$ & \\
\hline 5 & Ferulic acid glucoside & $355 / 193$ & \\
\hline 6 & Epicatechin & $289 / 245$ & \\
\hline 7 & Myricetin glucuronide & $493 / 317 ; 179$ & \\
\hline 8 & Cyanidin-3-0-glucoside & & $449 / 287$ \\
\hline 9 & Cyanidin-3-0-rutinoside & & $595 / 287$ \\
\hline 10 & Myricetin rutinoside & $625 / 317$ & \\
\hline 11 & Taxifolin glucoside & $465 / 303 ; 151$ & \\
\hline 12 & Epigallocatechin gallate or gallocatechin gallate & $441 / 289$ & \\
\hline 13 & Myricetin-rhamnoside & $463 / 317$ & \\
\hline 14 & Rutin & $609 / 301$ & \\
\hline 15 & Quercetin glucuronide & $477 / 301$ & \\
\hline 16 & Quercetin rhamnoside & $447 / 301$ & \\
\hline 17 & Kaempferol rutinoside & $593 / 285$ & \\
\hline 18 & Phloridzin & $435 / 273$ & \\
\hline 19 & Myricetin glucoside glucuronide & $479 / 316$ & \\
\hline 20 & Deoxyrhapontin & $403 / 241$ & \\
\hline 21 & Quercetin glucoside & $463 / 301$ & \\
\hline 22 & 9S,12S,13S-trihydroxy-10E-octadecenoic acid (9,12,13-TriHOME) & $329 / 171 ; 229$ & \\
\hline Peak no. & The most abundant compounds in Ribes nigrum berries & {$[\mathrm{M}-\mathrm{H}]-/$ fragments } & {$[\mathrm{M}+\mathrm{H}]+/$ fragments } \\
\hline 1 & Chlorogenic acid & $353 / 191 ; 179$ & \\
\hline 2 & Caffeic acid-O-glucoside & 345 & \\
\hline 3 & Coumaryl quinic acid & $(341) / 179 ; 161$ & \\
\hline 4 & Delphinidin-3-0-glucoside & $337 / 191$ & $465 / 303$ \\
\hline 5 & Delphinidin-3-0-rutinoside & & $611 / 465 ; 303$ \\
\hline 6 & Cyanidin-3-0-glucoside & & $449 / 287$ \\
\hline 7 & Cyanidin-3-0-rutinoside & & $595 / 287$ \\
\hline 8 & Isorhamnetin-3-0-rutinoside & & $625 / 317$ \\
\hline 9 & Myricetin-0-glucoside & & $481 / 319$ \\
\hline 10 & Rutin & $609 / 301$ & $611 / 303$ \\
\hline Peak no. & The most abundant compounds in Aronia melanocarpa berries & {$[\mathrm{M}-\mathrm{H}]$-/fragments } & {$[\mathrm{M}+\mathrm{H}]+$ /fragments } \\
\hline 1 & Chlorogenic acid I & $353 / 191 ; 179$ & $355 / 163$ \\
\hline 2 & Cyanidin3,5-di-0-glucoside & & $611 / 287$ \\
\hline 3 & Chlorogenic acid II & $353 / 191 ; 179$ & $355 / 163$ \\
\hline 4 & Cyanidin-3-0-glucoside & & $449 / 287$ \\
\hline 5 & Cyanidin-3-0- $\alpha$-arabinopyranoside & & $419 / 287$ \\
\hline 6 & Cyanidin-3-0- $\alpha$-arabinopyranoside & & $419 / 287$ \\
\hline 7 & Delphinidin-3-0-(2“-0- $\beta$-xylopyranosyl)- $\beta$-glycopyranoside & & $596 / 303$ \\
\hline 8 & Eriodictyol-7-0- $\beta$-glycuronide & & $465 / 289$ \\
\hline 9 & Rutin & $609 / 301$ & $611 / 303$ \\
\hline 10 & Delphinidin-3-0-glucopyranoside & & $465 / 303$ \\
\hline Peak & The most abundant compounds in Lonicera caerulea berries & [M-H]-/fragments & {$[\mathrm{M}+\mathrm{H}] \mathrm{H} /$ fragments } \\
\hline 1 & Cyanidin3,5-di-0-glucoside & & $611 / 449 ; 287$ \\
\hline 2 & Cyanidin3,5-di-0-glucoside isomer & & $611 / 449 ; 287$ \\
\hline 3 & Chlorogenic acid & $353 / 191 ; 179$ & $355 / 163$ \\
\hline 4 & Cyanidin-3-0-glucoside & & $449 / 287$ \\
\hline 5 & Cyanidin 3-0-rutinoside & & $595 / 287$ \\
\hline 6 & Peonidin 3-0-glucoside & & $463 / 301$ \\
\hline 7 & Quercetin 0-rhamnoside-0-glucoside & & $609 / 463$ \\
\hline
\end{tabular}


Table 3. Antibacterial activity of plant infusions against Gram-positive bacteria (inhibition zones $(\mathrm{mm}) \pm$ standard deviation)

\begin{tabular}{|c|c|c|c|c|c|c|c|c|c|c|c|}
\hline \multirow[t]{2}{*}{ Plant infusions } & \multirow{2}{*}{$\begin{array}{l}\text { Conc. } \\
(\mathrm{w} / \mathrm{v})\end{array}$} & \multicolumn{2}{|c|}{ B. cereus } & \multicolumn{2}{|c|}{ B. pumilus } & \multicolumn{2}{|c|}{ B. subtilis } & \multicolumn{2}{|c|}{ K. rhizophila } & \multicolumn{2}{|c|}{ L. monocytogenes } \\
\hline & & $\mathrm{A}$ & $\mathrm{B}$ & $\mathrm{A}$ & $\mathrm{B}$ & $\mathrm{A}$ & B & $\mathrm{A}$ & $\mathrm{B}$ & $\mathrm{A}$ & $\mathrm{B}$ \\
\hline \multirow{4}{*}{$\begin{array}{l}\text { The dark roots of } \\
\text { rhubarb } 303\end{array}$} & $1: 20$ & 16 & $15.5 \pm 2.1$ & $11^{*}$ & $13.5 \pm 0.7$ & 11 & 14 & 11 & $13.5 \pm 0.7$ & 9 & $11.5 \pm 0.7$ \\
\hline & $1: 40$ & 15 & $12.5 \pm 0.7$ & $8^{*}$ & $11.5 \pm 0.7$ & - & $12 \pm 3$ & 10 & $11 \pm 2$ & 7 & 10 \\
\hline & $1: 80$ & 11 & $11.5 \pm 0.7$ & $8^{*}$ & $11.5 \pm 2.1$ & - & $9 \pm 1.4$ & - & $9 \pm 2$ & - & $8.5 \pm 0.7$ \\
\hline & $1: 160$ & 10 & 9 & - & 9 & - & 8 & - & $9 *$ & - & 8 \\
\hline \multirow{4}{*}{$\begin{array}{l}\text { Petioles of } \\
\text { rhubarb } 303\end{array}$} & $1: 20$ & $11.5 \pm 0.71$ & 12 & - & $9 *$ & - & 10 & 9 & 10 & - & 12 \\
\hline & $1: 40$ & 10 & $9.5 \pm 0.7$ & - & $8^{*}$ & - & $10^{*}$ & - & $9 *$ & - & 10 \\
\hline & $1: 80$ & 10 & 10 & - & $7^{*}$ & - & - & - & - & - & $8.5 \pm 0.7$ \\
\hline & $1: 160$ & 8 & 8 & - & - & - & - & - & - & - & 6 \\
\hline \multirow{4}{*}{$\begin{array}{l}\text { The pale roots of } \\
\text { rhubarb 'Ogres' }\end{array}$} & $1: 20$ & 10 & 10 & - & 10 & - & - & - & - & - & 12 \\
\hline & $1: 40$ & 8 & 9 & - & 8 & - & - & - & - & - & 10 \\
\hline & $1: 80$ & 7 & 8 & - & - & - & - & - & - & - & 8 \\
\hline & $1: 160$ & 0 & - & - & - & - & - & - & - & - & - \\
\hline \multirow{4}{*}{$\begin{array}{l}\text { Petioles of light } \\
\text { rhubarb 'Ogres' }\end{array}$} & $1: 20$ & 10 & 11 & - & - & - & - & - & 8 & - & 8 \\
\hline & $1: 40$ & $8.5 \pm 0.7$ & 10 & - & - & - & - & - & - & - & 7 \\
\hline & $1: 80$ & $7.5 \pm 0.7$ & 9 & - & - & - & - & - & - & - & 6 \\
\hline & $1: 160$ & - & 7 & - & - & - & - & - & - & - & 0 \\
\hline \multirow{4}{*}{$\begin{array}{l}\text { Roots of rhubarb } \\
\text { 'Victoria' }\end{array}$} & $1: 20$ & 13 & 14 & 9 & 11 & 9 & $13^{*}$ & $10^{*}$ & $12 *$ & - & 12 \\
\hline & $1: 40$ & 12 & 12 & 8 & 9 & $9 *$ & $11^{*}$ & $8^{*}$ & $9^{*} \pm 2$ & - & 8 \\
\hline & $1: 80$ & 8 & 11 & - & 7 & - & - & - & - & - & 7 \\
\hline & $1: 160$ & - & 10 & - & - & - & - & - & - & - & 6 \\
\hline \multirow{4}{*}{$\begin{array}{l}\text { Petioles of } \\
\text { rhubarb 'Victoria' }\end{array}$} & $1: 20$ & 12 & 10 & - & $11^{*}$ & - & - & - & - & - & $11 \pm 2$ \\
\hline & $1: 40$ & 9 & 9 & - & $11^{*}$ & - & - & - & - & - & 9 \\
\hline & $1: 80$ & 7 & 7 & - & - & - & - & - & - & - & 8 \\
\hline & $1: 160$ & - & - & - & - & - & - & - & - & - & 7 \\
\hline \multirow{4}{*}{$\begin{array}{l}\text { Berries of black } \\
\text { currant 'Ben } \\
\text { Alder' }\end{array}$} & $1: 20$ & 12 & $10^{*}$ & - & $10 \pm 2$ & - & 9 & $8 \pm 2 *$ & 9* & - & $11 \pm 2$ \\
\hline & $1: 40$ & 10 & $9 *$ & - & - & - & 7 & - & - & - & 7 \\
\hline & $1: 80$ & 7 & - & - & - & - & - & - & - & - & - \\
\hline & $1: 160$ & - & - & - & - & - & - & - & - & - & - \\
\hline \multirow{4}{*}{$\begin{array}{l}\text { Leaves of black } \\
\text { currant 'Pamjati } \\
\text { Vavilova' }\end{array}$} & $1: 20$ & 14 & $10.5 \pm 0.7$ & $8^{*}$ & - & - & $8^{*}$ & - & - & - & 10 \\
\hline & $1: 40$ & 13 & 9 & $7 *$ & - & - & - & - & - & - & 9 \\
\hline & $1: 80$ & 10 & 8 & $6^{*}$ & - & - & - & - & - & - & 9 \\
\hline & $1: 160$ & 8 & 7 & - & - & - & - & - & - & - & 8 \\
\hline \multirow{4}{*}{$\begin{array}{l}\text { Berries of black } \\
\text { chokeberry }\end{array}$} & $1: 20$ & 10 & 12 & - & $10^{*}$ & - & - & - & $12^{*}$ & - & $10.5 \pm 0.7$ \\
\hline & $1: 40$ & 8 & 10 & - & $10^{*}$ & - & - & - & $11^{*}$ & - & 8 \\
\hline & $1: 80$ & 7 & 9 & - & - & - & - & - & - & - & 7 \\
\hline & $1: 160$ & - & 7 & - & - & - & - & - & - & - & 6 \\
\hline \multirow{4}{*}{$\begin{array}{l}\text { Berries of blue } \\
\text { honeysuckle } \\
\text { 'Tomitška' }\end{array}$} & $1: 20$ & $10^{*}$ & 10 & - & $9 *$ & - & - & - & - & - & - \\
\hline & $1: 40$ & - & 8 & - & $8^{*}$ & - & - & - & - & - & - \\
\hline & $1: 80$ & - & 7 & - & $7 *$ & - & - & - & - & - & - \\
\hline & $1: 160$ & - & - & - & $7 *$ & - & - & - & - & - & - \\
\hline Control (-) & & - & - & - & - & - & - & - & - & - & - \\
\hline \multicolumn{2}{|l|}{ Control (+) } & \multicolumn{2}{|c|}{$29 \pm 2$} & \multicolumn{2}{|c|}{$28.5 \pm 3$} & \multicolumn{2}{|c|}{$33 \pm 2$} & & & & \\
\hline
\end{tabular}

- No visible growth detected; *bacteriostatic effect was detected; A -20\% ethanol-plant infusion; B $-96 \%$ ethanol-plant infusion 
Table 4. Antibacterial activity of plant infusions against Gram-negative bacteria (inhibition zones $(\mathrm{mm}) \pm$ standard deviation)

\begin{tabular}{|c|c|c|c|c|c|c|c|c|c|}
\hline \multirow[t]{2}{*}{ Plant infusions } & \multirow{2}{*}{$\begin{array}{l}\text { Conc. } \\
(\mathrm{w} / \mathrm{v})\end{array}$} & \multicolumn{2}{|c|}{ C. jejuni } & \multicolumn{2}{|c|}{ S. Enteritidis } & \multicolumn{2}{|c|}{ E. coli } & \multicolumn{2}{|c|}{ Y. ruckeri } \\
\hline & & $\mathrm{A}$ & $\mathrm{B}$ & $\mathrm{A}$ & $\mathrm{B}$ & $\mathrm{A}$ & B & $\mathrm{A}$ & $\mathrm{B}$ \\
\hline The dark roots of rhubarb & $1: 20$ & - & $18 \pm 3$ & $10^{*}$ & $11.5 \pm 0.7$ & $10^{*}$ & $11 \pm 1.4$ & 8 & 9* \\
\hline \multirow[t]{3}{*}{303} & $1: 40$ & - & $13.5 \pm 0.7$ & - & 10 & - & 9 & 7 & $8 *$ \\
\hline & $1: 80$ & - & 12 & - & 8 & - & 8 & - & - \\
\hline & $1: 160$ & - & 10 & - & 7 & - & 7 & - & - \\
\hline \multirow[t]{4}{*}{ Petioles of rhubarb 303} & $1: 20$ & - & 12 & - & $11 \pm 2$ & - & $11.5 \pm 0.7$ & 17 & $16 \pm 2$ \\
\hline & $1: 40$ & - & 11 & - & $9.5 \pm 0.7$ & - & 9 & 14 & 12 \\
\hline & $1: 80$ & - & 10 & - & 9 & - & 8 & 9 & 9 \\
\hline & $1: 160$ & - & 8 & - & 8 & - & $7.5 \pm 0.7$ & - & - \\
\hline The pale roots of rhubarb & $1: 20$ & - & 16 & - & 12 & - & 12 & - & 12 \\
\hline \multirow{3}{*}{ 'Ogres' } & $1: 40$ & - & 15 & - & 10 & - & 10 & - & 10 \\
\hline & $1: 80$ & - & 14 & - & - & - & - & - & 8 \\
\hline & $1: 160$ & - & 10 & - & - & - & - & - & - \\
\hline \multirow[t]{4}{*}{ Petioles of rhubarb 'Ogres' } & $1: 20$ & - & 12 & - & $12 *$ & - & 10 & $10^{*}$ & 14 \\
\hline & $1: 40$ & - & 11 & - & $9 *$ & - & 9 & $8^{*}$ & 9 \\
\hline & $1: 80$ & - & - & - & $8^{*}$ & - & 7 & - & - \\
\hline & $1: 160$ & - & - & - & - & - & - & - & - \\
\hline \multirow[t]{4}{*}{ Roots of rhubarb 'Victoria' } & $1: 20$ & - & $18 \pm 2$ & 8 & $11.5 \pm 0.7$ & 8 & $11.5 \pm 0.7$ & 14 & 9 \\
\hline & $1: 40$ & - & 15 & 6 & 10 & - & $10 \pm 2$ & 10 & $8^{*}$ \\
\hline & $1: 80$ & - & 13 & - & 9 & - & 9 & - & - \\
\hline & $1: 160$ & - & 10 & - & 8 & - & 8 & - & - \\
\hline \multirow[t]{4}{*}{ Petioles of rhubarb 'Victoria' } & $1: 20$ & - & 8 & - & 9 & - & 9 & $13 \pm 3$ & 8 \\
\hline & $1: 40$ & - & 7 & - & 8 & - & 8 & - & - \\
\hline & $1: 80$ & - & - & - & 7 & - & 7 & - & - \\
\hline & $1: 160$ & - & - & - & 7 & - & 7 & - & - \\
\hline Berries of black currant 'Ben & $1: 20$ & - & $15 \pm 2$ & - & 10 & - & 10 & 10 & $12 \pm 2$ \\
\hline \multirow[t]{3}{*}{ Alder' } & $1: 40$ & - & $13 \pm 2$ & - & 9 & - & 9 & $8^{*}$ & 9 \\
\hline & $1: 80$ & - & 12 & - & - & - & - & - & - \\
\hline & $1: 160$ & - & 12 & - & - & - & - & - & - \\
\hline Leaves of black currant & $1: 20$ & - & 13 & - & $9.5 \pm 0.7$ & - & 11 & $12^{*}$ & $10^{*}$ \\
\hline \multirow[t]{3}{*}{ 'Pamjati Vavilova' } & $1: 40$ & - & 11 & - & 9 & - & 10 & $8^{*}$ & $8^{*}$ \\
\hline & $1: 80$ & - & 10 & - & 8 & - & 9 & - & - \\
\hline & $1: 160$ & - & 9 & - & 8 & - & 8 & - & - \\
\hline \multirow[t]{4}{*}{ Berries of black chokeberry } & $1: 20$ & 10 & 15 & - & $9 \pm 2$ & - & 11 & - & $8^{*}$ \\
\hline & $1: 40$ & 8 & 12 & - & 7 & - & 11 & - & - \\
\hline & $1: 80$ & - & 10 & - & 7 & - & 11 & - & - \\
\hline & $1: 160$ & - & 8 & - & 6 & - & 8 & - & - \\
\hline Berries of blue honeysuckle & $1: 20$ & 15 & $14 \pm 2$ & - & 9 & - & $8.5 \pm 0.5$ & $9 *$ & 10 \\
\hline \multirow[t]{3}{*}{ 'Tomitška' } & $1: 40$ & 10 & 13 & - & 7 & - & 7 & $7 *$ & 7 \\
\hline & $1: 80$ & 8 & 8 & - & - & - & - & - & - \\
\hline & $1: 160$ & - & - & - & - & - & - & - & - \\
\hline Control (-) & & - & - & - & - & - & - & - & - \\
\hline Control (+) & & & & & & & & & \\
\hline
\end{tabular}

-No visible growth detected; *bacteriostatic effect was detected; A -20\% ethanol-plant infusion; B -96\% ethanol-plant infusion 